\title{
Individual and Social Influences on College Student Compliance with a Gluten-Free Diet
}

\author{
Crystal Sparks ${ }^{1}$, Taylor Zingg ${ }^{2}$, Marshall K. Cheney ${ }^{2, *}$ \\ ${ }^{1}$ Oklahoma State University Center for Health Sciences, Tulsa, Oklahoma, USA \\ ${ }^{2}$ Department of Health and Exercise Science, University of Oklahoma, Norman, Oklahoma, USA \\ *Corresponding author: marshall@ou.edu
}

Received October 02, 2019; Revised November 06, 2019; Accepted December 04, 2019

\begin{abstract}
The objective of this study was to examine individual and social influences on college student compliance with a gluten-free diet. Individual semi-structured interviews were conducted in 2016-2017 with undergraduates $(n=24)$ at a large public university. Eligible participants were 18-25 years old with self-reported physician-diagnosed celiac disease. The interview question path was based on the Health Belief Model and assessed individual and social influences on eating choices. Transcribed interviews were independently coded by three researchers (ICR=.82) then analyzed for themes using the Health Belief Model as a guiding framework. Barriers to complying with a gluten-free diet included the college meal plan, meal planning and cooking skills, negotiating social interactions around food, financial burden of purchasing gluten-free food, and intentionally eating gluten as self-confidence grew. Students often reframed non-compliance as a "cheat day," discussing it as they would a reduced-calorie diet, which could reduce perceived threat. Providers discussed threats to health in terms of long-term outcomes but students focused on the immediate impact of eating gluten. Nutritionists, parents, and health care providers can better prepare college students for the transition to independent food choices and how to remain compliant with a gluten-free diet within the challenging college food environment.
\end{abstract}

Keywords: celiac, gluten, college, young adult, health belief model

Cite This Article: Crystal Sparks, Taylor Zingg, and Marshall K. Cheney, "Individual and Social Influences on College Student Compliance with a Gluten-Free Diet.” International Journal of Celiac Disease, vol. 7, no. 3 (2019): 78-83. doi: 10.12691/ijcd-7-3-6.

\section{Introduction}

Celiac disease is an autoimmune disease that leads to abnormal responses to ingested gluten, leading to damage in the small intestine as well as malabsorption of nutrients such as iron, calcium, carbohydrates, and fat-soluble vitamins. [1-4] Untreated celiac disease increases the risk of esophageal cancer, colon cancer, cardiovascular disease, additional autoimmune diseases, nutritional deficiencies, osteoporosis, infertility, and depression. [1,4,5] About 1 in 100 people are diagnosed with celiac disease. [6,7] The prevalence of celiac disease is increasing in the U.S. due to increased awareness and better diagnostic techniques, however researchers estimate that for each diagnosed case of celiac disease there may be 3-7 undiagnosed cases. $[1,3,5,7,8,9]$

The current treatment for celiac disease is to eliminate gluten from the diet. This involves major lifestyle changes and changes in daily habits. [1,10] Estimates of strict adherence to a gluten free diet range from $42 \%$ to $91 \%$, depending on the study population and how compliance was defined and measured in the study. [3,5,7,11,12] Intentionally eating gluten is most likely during social situations including eating outside the home. [1,8,13,14,15]
One in five adolescents and adults with celiac disease said they eat food containing gluten at least once a month. [16]

There is also a social cost to living with celiac disease. Most adults with celiac disease said that following a gluten-free diet had a negative impact on their social and family life, limiting their social activities and how much they could enjoy them, or being left out of social occasions because of their dietary restrictions. [1,13,16-21] Many adolescents and adults with celiac disease report feeling uncomfortable or embarrassed following their diet in social settings. $[14,15,20]$ Living with celiac disease can also have psychological impacts on adolescents and adults, leading to feelings of frustration, depression, or feeling different from other people. [13,16,18] Children and adults also experienced anxiety over their constant monitoring of what they eat, and most (68\%) said this reduced their enjoyment of food. [7,16,20]

College attendance represents a transition to more independent decision making for young adults where they establish behavior patterns that they carry with them into adulthood. [22] How college students manage their celiac disease as they establish independence from their parents is critical for lifelong compliance with a gluten free diet. The objective of this study was to examine individual and social influences on college student compliance with a gluten free diet. 


\section{Methods}

\subsection{Development of the Interview Guide}

Interview questions were developed based on a review of the literature and an interview with a young adult diagnosed with celiac disease (not included in the study sample). The semi-structured interview guide contained questions based on the Health Belief Model constructs of perceived susceptibility to short- and long-term health effects from eating gluten, perceived severity of symptoms, facilitators and barriers to eat a gluten-free diet, self-efficacy, and cues to eating gluten-containing foods. [23] Additional questions about social influences, campus food options, and knowledge of gluten-containing foods addressed factors specific to college students. The interview guide was then tested with a convenience sample of college students with a gluten allergy or celiac disease (not included in the current study sample) for understandability, question structure, and ordering.

\subsection{Sample}

Undergraduate college students attending a large public university in the southwest United States were eligible to participate in the study if they were:

- Currently enrolled undergraduate between 18 and 25 years old

- Had a physician diagnosis of celiac disease or non-celiac gluten sensitivity (Both conditions require a complete elimination of gluten from the diet and similar lifestyle changes [1]).

The University of Oklahoma Institutional Review Board approved the study.

\subsection{Recruitment}

Purposive sampling methods were used to actively recruit participants who could meaningfully contribute to investigator understanding of the experience of eating a gluten-free diet. [24] Recruitment posters were placed on campus and on electronic posting sites in 2016-2017.

\subsection{Data Collection}

Two interviewers trained in qualitative data collection methods interviewed participants at a campus location of their choice (usually a library study room). The interview process consisted of a written informed consent and a brief demographic questionnaire followed by the interview (lasting around 45 minutes). Students received a \$15 store gift card for their participation. Meaning saturation was reached at interview 20 (when no new information was heard within the theoretical constructs) $[24,25]$ then an additional 4 interviews were conducted to confirm saturation.

\subsection{Data Analysis}

The audio-recorded interviews were transcribed then checked against the recording for accuracy. Next, the interviews were reviewed for interview quality and consistency in questioning across participants. NVivo v.11 software was used to code the transcripts. Three coders developed the initial codebook based on a first reading of the transcripts and a review of the literature. The team coded three transcripts together then revised the codebook. The remaining 21 transcripts were coded independently. A second coding pass used Health Belief Model constructs. The team met to identify and discuss coding differences until consensus was reached $(\mathrm{ICR}=.82)$.

The researchers used both an inductive and deductive approach to thematic analysis. [26] During the inductive process the research team read the coded text individually and independently identified "themes" or patterns that emerged across participants without imposing any theoretical framework. This was followed by a deductive approach, where themes were identified within the Health Belief Model (HBM) framework. Following theme identification, the transcripts were reviewed again to select representative quotes. Transcripts were reviewed a final time for disconfirming evidence of themes. [27] A student with celiac disease then conducted a final review of the themes and quotes for representativeness.

\section{Results}

\subsection{Participants}

Participants ranged in age from 18 to 22, mean age $=$ 19.8 years old (see Table 1 ). Three quarters of participants were female, and about half were freshman or sophomores. About half were diagnosed just before or during college (see Table 1). Almost all came from highly-educated families. Most participants (75\%) said that they adhered to a gluten free diet "all the time" and did not have a close friend who also ate a gluten-free diet.

Table 1. Participant Characteristics

\begin{tabular}{|c|c|c|}
\hline Characteristic & \multicolumn{2}{|c|}{ N (\%) } \\
\hline \multicolumn{3}{|l|}{ Age } \\
\hline $18-19$ & \multicolumn{2}{|c|}{$11(45 \%)$} \\
\hline $20-22$ & \multicolumn{2}{|c|}{$13(55 \%)$} \\
\hline \multicolumn{3}{|l|}{ Gender } \\
\hline Female & \multicolumn{2}{|c|}{$19(79 \%)$} \\
\hline Male & \multicolumn{2}{|c|}{$5(21 \%)$} \\
\hline Parent Education & Mother & Father \\
\hline$<$ high school & $1(4 \%)$ & 0 \\
\hline High school & $3(13 \%)$ & $1(4 \%)$ \\
\hline Technical school/some college & $2(8 \%)$ & $4(17 \%)$ \\
\hline College or higher & $18(75 \%)$ & $18(75 \%)$ \\
\hline Not listed & 0 & $1(4 \%)$ \\
\hline \multicolumn{3}{|l|}{ Age at diagnosis } \\
\hline $10-14$ & \multicolumn{2}{|c|}{$4(17 \%)$} \\
\hline $15-17$ & \multicolumn{2}{|c|}{9 (38\%) } \\
\hline $18-19$ & \multicolumn{2}{|c|}{$9(38 \%)$} \\
\hline $20-21$ & \multicolumn{2}{|c|}{$2(8 \%)$} \\
\hline $\begin{array}{l}\text { Stick to a gluten free diet all the time (Yes) } \\
\text { \# of } 5 \text { closest friends who eat gluten-free }\end{array}$ & \multicolumn{2}{|c|}{$18(75 \%)$} \\
\hline 0 & \multicolumn{2}{|c|}{$15(63 \%)$} \\
\hline 1 & \multicolumn{2}{|c|}{$2(8 \%)$} \\
\hline 2 & \multicolumn{2}{|c|}{$3(13 \%)$} \\
\hline 3 or more & \multicolumn{2}{|c|}{$4(17 \%)$} \\
\hline \multicolumn{3}{|l|}{ \# days a week usually eat out } \\
\hline 0 & \multicolumn{2}{|c|}{0} \\
\hline 1 & \multicolumn{2}{|c|}{$16(67 \%)$} \\
\hline 2 & \multicolumn{2}{|c|}{$4(17 \%)$} \\
\hline 3 or more & \multicolumn{2}{|c|}{$4(17 \%)$} \\
\hline
\end{tabular}




\subsubsection{Perceived Threat (Susceptibility and Severity)}

When perceived threat was high, compliance with a gluten-free diet was high. This was largely driven by immediate severity of symptoms experienced when eating gluten rather than information from health care providers about long term health consequences. Students were aware of diseases that could be caused by eating gluten but these were too far in the future to be threatening.

sometimes when I think about how much damage I'm going to do to my body if I keep eating gluten and that makes me feel bad. But not really...my doctor was trying to freak me out, but he was like, you have a $90 \%$ increase of having colon cancer if you keep eating gluten...that didn't personally freak me out. I was just like, oh, yeah cancer's bad. \#19

More motivating were immediate symptoms they experienced that had a negative social impact such as eczema or severe GI symptoms in social situations. Those with more severe reactions to gluten described constantly reading food labels, watching and questioning how their food was prepared, and checking the ingredients in everything that touched their body.

it's difficult...literally everything I put in or on my body, like my shampoos, my makeups, my toothpaste...things that you wouldn't even think about them having in there I have to intensely research. \#10

However, some students admitted that after being compliant with their gluten-free diet for a long time with no symptoms, their perceived threat was reduced to the point that they felt it was acceptable to try a small amount of gluten to see how they tolerated it.

\subsubsection{Barriers}

One of the biggest barriers to complying with a gluten-free diet was when food choices were out of their control. The majority of students said that they usually planned to eat some gluten during holidays, particularly if they were staying at the home of a relative. Students discussed weighing their options of going without food against the severity of their symptoms as well as the social consequences of not eating food that was offered to them. Students who were successful in adhering to a gluten free diet discussed strategies such as calling the host before the visit to make suggestions for safe meals and bringing their own food.

Restaurants can be a particular barrier to complying with a gluten-free diet yet all of the students said that they eat at a restaurant at least once a week. Strategies students used in these situations included checking the menu beforehand, calling ahead to ask questions, bringing something with them to eat, meeting friends after meals, or inviting someone else who has a food limitation. Students said when more than one person in the group had a dietary limitation, it was easier to direct the group's restaurant choices. Students reported frequent interactions where the servers did not take them seriously. Some students reported that they sometimes ate food without knowing if it was gluten free. They felt at that point that their choice was to be "difficult" (especially for females) or to get sick. Students also described stressful social interactions with friends over restaurant choices and feeling like a burden to their friends who had to accommodate their special dietary needs.

they're like oh, we can't eat here because you have this and that and so I'm like oh no I'll have this once and I'll be fine...I always feel bad to be that friend. \#9

Others talked about celiac disease not being taken seriously as a problem by friends or teammates who belittled it. One male participant reported being teased by other members of his sports team as "being soft" because he would not eat foods with gluten.

most people think of it as things that girls do just to lose weight...I'd say it's looked down upon for a guy to do it, but it's been fine once I tell them that I have to do it, they're understanding about it. \#11

The transition from home to school was especially difficult for those students whose parents had taken charge of their diet after their diagnosis, purchasing safe foods, preparing meals, and making most of the food decisions for them. These students struggled to stay compliant once they had independence in their food choices, particularly students with limited cooking skills.

Students also expressed frustration about the high cost of gluten-free foods and felt guilty about the financial burden this placed on their parents. Some students had a fixed monthly budget which they usually spent on more expensive but safer foods but this often came at the expense of social activities or costs related to school. In many cases, students said that they purchased cheaper foods with gluten in them to stay within their monthly budget.

They [my parents] tell me to just buy it anyways but there is $t$-shirts and other things I want too... my symptoms have kind of changed so it is difficult to really force myself to buy the more expensive stuff...It is kind of like priorities. \#12

\subsubsection{Facilitators}

Most students said that their good friends were considerate of their restrictions and provided advocacy and social support for their dietary needs.

she is one of my best friends for the past 5 years so she knows and she is very aware of what I am supposed to eat and when I am not supposed to eat...why are you eating that you are not supposed to eat that I know you are not supposed to don't tell me you can \#12

Developing good planning skills around food can make it easier to stay compliant. Students discussed making meals ahead of time, cooking enough for several meals each time they cooked, and bringing their lunch, snacks, and even dinner to school each day. Participants emphasized the importance of always having several snacks with them so that they would not be confronted with a situation of no good food options when they were hungry.

\subsubsection{Self-Efficacy}

Perceived self-efficacy for eating gluten-free foods seemed to be related to both a longer time since diagnosis 
and greater severity of symptoms experienced. Still, most students expressed confidence in their ability to stay compliant with their gluten-free diet, even if they chose not to. Living alone increased self-efficacy as participants said they had more control over their food. Becoming more educated about gluten-free foods and how to cook without gluten increased student confidence in their ability to eat gluten-free foods. However, for many students, greater self-efficacy also seemed to put them at risk for eating gluten-containing foods. Their increased confidence in their knowledge and management of their disease, coupled with decreased symptoms due to their good management, seemed to make them more receptive to eating gluten.

the intestines have grown back a little bit I think is what they explained to me and I am stronger so I can tolerate it more \#21

I: So how confident do you feel in your ability to resist foods with gluten in them?

P: From 1-10 10 being the most confident. 10.

I: So how often do you stick to a gluten free diet?

P: I would say more often then not. \#7

\subsubsection{Cues to Action}

Students discussed cues to action to both eat gluten and cues to adhere to a gluten-free diet. Most of the cues to eat gluten came from situations where they ate outside of the home, such as menus or another person's food order. However, a friend who advocated for their needs at restaurants was an important cue to stay compliant. Several students said living with another student who has some type of dietary limitation (not necessarily gluten) made it much easier to resist gluten containing foods. Students were also cued by friends, co-workers, and coaches who encouraged them to try gluten-containing foods to see if their bodies could "handle it" or to see if they had "outgrown" their reaction to gluten.

I actually was talking to one of my supervisors and he was saying...I would just be really interested to see if you could handle a cracker a day and see if you could progress... a lot of people have asked me if I could just go ahead and try it and try re-introducing it. \#13

\subsubsection{Cheat Days}

Those with milder reactions discussed planned or unplanned "cheat days" where they would eat some of their favorite foods that contained gluten. Framing noncompliance as a "cheat day" (like they would higher calorie foods while on a calorie-restricted diet) lowered the perceived threat of eating gluten and any guilt they experienced. A common strategy was to plan times when they would eat a little gluten so that their symptoms would occur over a weekend or at home and not interfere with a test or social event. None of these students had talked with a nutritionist or physician about these behaviors.

I probably have a little bit of gluten three times a week...I'll have like one chicken strip...It's kind of my cheat. I'll be like, I need one. And usually if I have a little bit, I won't experience severe enough side effects for me to feel bad about it. \#19

\subsubsection{Campus}

Most students found it difficult to adhere to a glutenfree diet on campus, primarily because gluten-free food was expensive and there were not many selections to choose from on their mandatory meal plan. Students also discussed the stress of adjusting their schedules to eat at times when "safe" restaurants were open. Students discussed incidents of cross-contamination of food on campus which they felt were unintentional by the kitchen staff and likely due to a lack of knowledge or training. A few discussed being reluctant to ask for special food preparation procedures because they felt they may be seen as "difficult."

I haven't gone a full week without having cross contamination or an attack. It has been a new adjustment. I will say that the university does try their hardest to help people with celiac \#25

Especially freshman year, they made me have a meal plan...they have gluten-free stuff, but they have like three different things...and I'm eating that every single day....I'll go up and I'll order something gluten-free and the workers are just like"uh" cause they know what they have to do and they have to clean everything and they just hate me. \#4

Living off campus allowed more control over what students ate and most moved off campus after their first year. Students said they were sick less often once they did not depend on campus food service to provide their meals, however, in other parts of the interview, students also complained about how long it takes to cook for yourself and the chronic stress of planning food to take to campus. Most participants did not know about resources available to them through campus Nutrition Services, including a nutritionist and a list of restaurants that served gluten-free options on campus. Those who were aware of these resources and used them said that the nutritionist was helpful.

\section{Discussion}

Young adulthood is a time when health behaviors are established and carried into adulthood, [22] but there are few behavioral interventions developed specifically to address the developmental and social challenges young adults face. [28] The constructs of the Health Belief Model provided a useful framework for structuring the question path, coding and interpreting data, and placing the findings within the college context. Barriers were the strongest theme across participants. Consistent with other studies, students found it difficult to adhere to a gluten free diet outside of the home and during social events that revolved around food,[13,19] but unlike adults, college students almost always chose to engage in social activities and reported eating out at least once a week, most two or more times a week. College student conversations in this study often reflected themes similar to adolescents in their difficulty negotiating social relationships and advocating for their needs, particularly when the "social cost" of compliance with a gluten free diet was high. [15] 


\subsection{Implications for Research and Practice}

\subsubsection{Recommendations for Parents}

Families could initiate a transition time between living at home and living at college, including cooking and shopping skills and practicing what to do in social situations. Consistent with other studies, students with limited financial resources found it difficult to stick to a gluten-free diet. $[8,14,16]$ College students often did not have enough money to both purchase high quality glutenfree food and have funds to participate in college activities, yet they felt guilty asking their parents for additional money. Students may need separate budgets for food and for social activities and parents should explicitly communicate that small increases in a food allowance to purchase healthy food is not a financial burden. One recommendation would be to provide grocery store gift cards so that students would not be tempted to use food money for social activities.

\subsubsection{Recommendations for Nutritionists and Health Care Providers}

While most students said that they complied with a gluten-free diet "all the time" on the written questionnaire before the interview, they later described intentionally eating gluten in specific situations. Providers are encouraged to ask young adult patients specifically about food choices at social events, restaurants, or when their budget is running low. Young adults with good symptom control should also be asked if they have occasionally eaten foods with gluten.

There was also a disconnect between how students perceived threat and how it was conveyed to them by their nutritionist or physician. The primary motivating factor for students for adhering to a gluten-free diet was avoidance of symptoms rather than to prevent any future significant health complications. This pattern is consistent with previous studies that showed immediate symptoms were the motivating factor in complying to a gluten-free diet rather than future health complications. [11,15] Nutritionists and other providers should consider shifting the primary focus of their messages to more immediate outcomes. Providers are also encouraged to maintain long-term follow up with patients diagnosed with celiac disease to monitor compliance with a gluten-free diet during college. $[11,28]$ College students often do not have an established health care provider when they come to college and most are transitioned out of their pediatrician's care at the age of 18 . $[8,11]$

\subsubsection{Recommendations for Campus Nutritionists and Nutrition Services Staff}

Campus nutritionists can work with parents of newly-accepted students to help prepare their children for the transition to independent living at school. The nutrition services staff can also initiate contact with new students with celiac disease to help them plan how to eat away from home and what campus options are available. Students with celiac disease or other dietary limitations may also benefit from additional orientation time when they arrive on campus and/or pair roommates by food restrictions. If possible, students with severely restricted diets could be released from the mandatory participation in the school meal plan so that they can prepare safer meals.

Previous researchers have recommended psychosocial support and greater dietician involvement to help both adolescents and adult adhere to a gluten-free diet. [3,7,8] Nutritionists are seen as a trusted source of information $[5,21]$ and a regular group meeting lead by the campus nutritionist could fulfill this role as well as increase student knowledge of gluten-free foods and give students the opportunity to talk through strategies and challenges. Nutritionists can also provide training to food services staff to help make campus options safer. There seemed to be limited knowledge of how to prepare food safely for students with celiac disease. This is consistent with previous studies of school cooks and community-based chefs and servers. [10,15,29] These trainings could also include food services staff and house staff from social sororities and fraternities. Finally, students with celiac disease could be part of the training for food services staff to share some of their experiences ordering gluten free food on campus. It is also recommended that nutritionists educate coaches, trainers, RAs, and other campus staff to ensure that they are not putting students at risk.

\subsection{Limitations}

While the study sample was relatively small, sample sizes are smaller for in-depth qualitative analysis and saturation was reached. This study was limited to one university, however the university hosts a diverse student population. Additional studies should be conducted to assess any geographical diversity in student experiences. The sample was also limited to college students and did not include young adults who were not in college.

\subsection{Conclusions}

Young adults face social and developmental challenges in learning to manage their celiac disease independently. It is important to recognize their cognitive and emotional abilities are still developing when they transition to independent living and often make choices that expose them to gluten-containing foods. Parents, nutritionists, health care providers, and campuses are important resources in helping college students adhere to a glutenfree diet as they transition from adolescence to young adulthood and establish healthy behaviors that they will carry into adulthood.

\section{Acknowledgements}

This project was supported by the University of Oklahoma. The authors would like to thank Leah Tanner for her assistance with the project.

\section{References}

[1] Zarkadas M, Cranney A, Case S, et al. The impact of a gluten-free diet on adults with coeliac disease: Results of a national survey. $J$ Hum Nutr Diet. 2006; 19: 41-49. 
[2] Veen M, te Molder H, Gremmen B, van Woerkum C. Quitting is not an option: An analysis of online diet talk between celiac disease patients. Health. 2010; 14(1): 23-40.

[3] Hall NJ, Rubin GP, Charnock A. Intentional and inadvertent nonadherence in adult coeliac disease. A cross-sectional survey. Appetite. 2013; 68: 56-62.

[4] Mulder CJ, Wierdsma N, Berkenpas M, Jacobs MAJM, Bouma G. Preventing complications in celiac disease: Our experience with managing adult celiac disease. Best Practice and Research Clinical Gastroenterology. 2015; 29: 459-468.

[5] Hall NJ, Rubin GP, Charnock A. Systematic review: Adherence to a gluten-free diet in adult patients with coeliac disease. Alimentary Pharmacology and Therapeutics. 2009; 30: 315-330.

[6] Dubé C, Rostom A, Sy R, et al. The prevalence of celiac disease in average-risk and at-risk Western European populations: A systematic review. Gastroenterology. 2005; 128: S57-S67.

[7] Watkins RD, Zawahir S. Celiac Disease and Nonceliac Gluten Sensitivity. Pediatr Clin North Am. 2017; 64: 563-576.

[8] Green PH, Cellier C. Celiac disease. N Engl J Med. 2007; 357: 1731-1743.

[9] Rewers M. Epidemiology of Celiac Disease: What are the prevalence, incidence, adn progression of Celiac Disease? Gastroenterology. 2005; 128: S47-S51.

[10] Karajeh MA, Hurlstone DP, Patel TM, Sanders DS. Chefs' knowledge of coeliac disease (compared to the publc): A questionnaire survey from the United Kingdom. Clinical Nutrition. 2005; 24: 206-210.

[11] O’Leary C, Wieneke P, Healy M, Cronin C, O’Regan P, Shanahan F. Celiac disease and the transition from childhood to adulthood: A 28-year follow-up. Am J Gastroenterol. 2004; 99: 2337-2441.

[12] Silvester JA, Weiten D, Graff LA, Walker JR, Duerksen DR. Is it gluten-free? Relationship between self-reported gluten-free diet adherence and knowledge of gluten content of foods. Nutrition. 2016; 32: 777-783.

[13] Black JL, Orfila C. Impact of coeliac disease on dietary habits and quality of life. J Hum Nutr Diet. 2011; 24: 582-587.

[14] Lee AR, Ng DL, Diamond B, Ciaccio EJ, Green PHR. Living with coeliac disease: Survey results from the USA. Clinical Nutrition. 2012; 25: 233-238.
[15] Olsson C, Hörnell A, Ivarsson A, Sydner YM. The everyday life of adolescent coeliacs: Issues of importance for compliance with the gluten-free diet. J Hum Nutr Diet. 2008; 21: 359-367.

[16] Whitaker JKH, West J, Holmes GKT, Logan RFA. Patient perceptions of the burden of coeliac disease and its treatment in the UK. Aliment Pharmacol Ther. 2009; 29: 1131-1136.

[17] Taylor E, Dickson-Swift V, Anderson K. Coeliac disease: The path to dianosis and the reality of living with the disease. J Hum Nutr Diet. 2012; 26.

[18] Addolorato G, Mirijello A, D’Angelo C, et al. Social phobia in Coeliac Disease. Scand J Gastroenterol. 2008; 43(4): 410-415.

[19] Hallert C, Sandlund O, Broqvist M. Perceptions of health-related quality of life of men and women living with coeliac disease. Scand J Caring Sci. 2003; 17: 301-307.

[20] Sverker A, Hensing G, Hallert C. "Controlled by food" - lived experiences of coeliac disease. J Hum Nutr Diet. 2005; 18: 171-180.

[21] Lee A, Newman JM. Celiac diet: Its impact on quality of life. J Am Diet Assoc. 2003; 103: 1533-1535.

[22] Arnett JJ. Emerging Adulthood: The Winding Road from the Late Teens Through the Twenties. New York: Oxford University Press; 2004.

[23] Champion VL, Skinner CS. The health belief model. In: Glanz K, Rimer BK, Viswanath $\mathrm{K}$, eds. Health Behavior and Health Education: Theory, Research, and Practice. (4th. ed, pp. 149-165). San Francisco, CA: Jossey-Bass; 2008.

[24] Patton MQ. Qualitative Research and Evaluation Methods: Integrating Theory and Practice. Los Angeles: Sage; 2014.

[25] Hennink MM, Kaiser BN, Marconi VC. Code saturation versus meaning saturation: How many interviews are enough? Qual Health Res. 2017; 27(4): 591-608.

[26] Ulin PR, Robinson ET, Tolley EE. Qualitative Methods in Public Health. San Francisco: Jossey-Bass; 2005.

[27] Miles MB, Huberman AM, Saldaña J. Qualitative Data Analysis. Thousand Oaks, CA: SAGE Publications, Inc; 2014.

[28] Institute of Medicine, National Research Council. Investing in the Health and Well-Being of Young Adults. Washington, D.C.: The National Academies Press. 2015.

[29] Bascuñán KA, Catalina Vespa M, Araya M. Celiac Disease: Understanding the gluten-free diet. Eur J Nutr. 2017; 56: 449-459.

(C) The Author(s) 2019. This article is an open access article distributed under the terms and conditions of the Creative Commons Attribution (CC BY) license (http://creativecommons.org/licenses/by/4.0/). 